\title{
Early Diagnosis of Bilateral Supplemental Primary and Permanent Maxillary Lateral Incisors: A Case Report
}

Gozde Yildirima

Sule Bayrak

\begin{abstract}
Supernumerary teeth occur frequently in permanent dentition, but they are rarely found in primary dentition. Supernumerary teeth of orthodox shape and size that resemble normal dentition are called 'supplemental teeth'. Supplemental teeth are less common than supernumerary teeth and are often overlooked because of their normal shape and size.

Supplemental teeth may cause esthetic problems, delayed eruption and crowding, and they require early diagnosis and treatment to prevent complications. The case reported here is one of bilateral supplemental teeth impeding the eruption of permanent maxillary lateral incisors, and it emphasizes the importance of early diagnosis and treatment during early mixed dentition. (Eur J Dent 2011;5:215-219]
\end{abstract}

Key words: Supernumerary teeth; Supplemental teeth; Lateral incisor.

\section{INTRODUCTION}

Supernumerary teeth are defined as teeth in excess of the normal dental formula. ${ }^{1-3}$ Supernumerary teeth occur less frequently in primary dentition than in permanent dentition. ${ }^{1,4-6}$ They have a reported prevalence of $1 \%-4 \%$ in permanent dentition ${ }^{2,3,6,7}$ and $0.2 \%-1.9 \%$ in primary dentition. ${ }^{1,3,8-10}$ Interestingly, $35 \%-50 \%$ of supernumerary teeth in primary dentition are superseded by extra teeth in

\footnotetext{
a Private Practice, Antalya, Turkey.

b Assistant Professor, Department of Pediatric Dentistry, Faculty of Dentistry,

Ondokuz Mayis University, Samsun, Turkey.
}

- Corresponding author: Sule Bayrak Department of Pediatric Dentistry, Faculty of Dentistry, Ondokuz Mayis University, 55139. Kurupelit, Samsun, Turkey.

Phone: +90 362 3121919/3365

Fax: +903624576032

E-mail: suleb76ayahoo.com the same location in the permanent dentition. ${ }^{11,12}$

Primosch ${ }^{1}$ classifies supernumerary teeth into two types according to shape. Supernumerary teeth of normal shape and size (eumorphic) are termed 'supplemental', or 'incisiform', whereas teeth of abnormal shape and smaller size (dysmorphic), are termed 'rudimentary' and include 'conical', 'tuberculate' and 'molariform' teeth.'

The case reported here - bilateral supplemental teeth that impeded the eruption of permanent maxillary lateral incisors - emphasizes the importance of early diagnosis and treatment during early mixed dentition.

\section{CASE REPORT}

An 8-year-old boy was referred to the pediatric dental clinic with the chief complaint of dental caries. The patient's medical history was non- 
contributory, there was no previous trauma to the teeth or jaws, and extraoral examination revealed no abnormality. The patient's mother had experienced no complications during pregnancy, and there was no family history of congenital anomalies.

Intraoral examination showed mixed dentition, together with bilateral supplemental primary maxillary lateral incisors (Figure 1). Panoramic and periapical radiographs revealed bilateral supplemental permanent maxillary lateral incisors underneath the bilateral supplemental primary maxillary lateral incisors (Figure 2).
All carious teeth were restored. The bilateral primary maxillary lateral incisors as well as the bilateral supplemental primary maxillary lateral incisors were extracted to facilitate the eruption of the permanent maxillary lateral incisors and the associated supplemental teeth. Regular follow-up was scheduled to monitor the eruption of the permanent lateral incisors and the associated supplemental teeth.

After 8 months of follow-up, the maxillary right distal lateral incisor had erupted, whereas the mesial lateral incisor had impacted (Figure 3), and the decision was made to extract the impact-

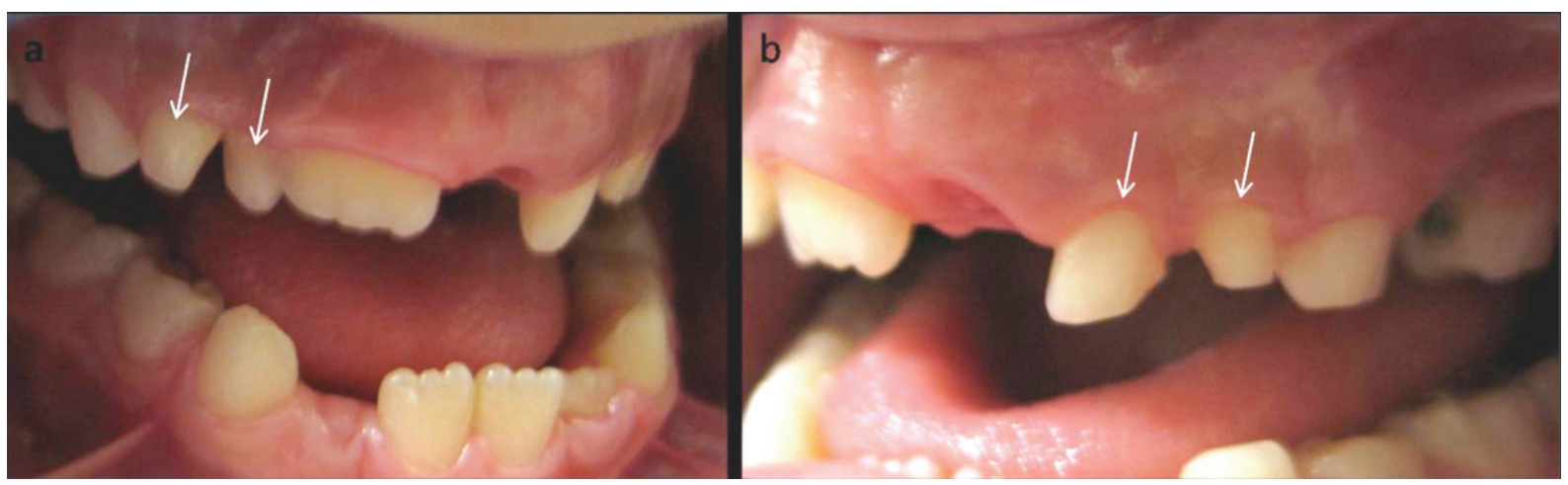

Figure 1. Intraoral photographs a. from right b. from left.

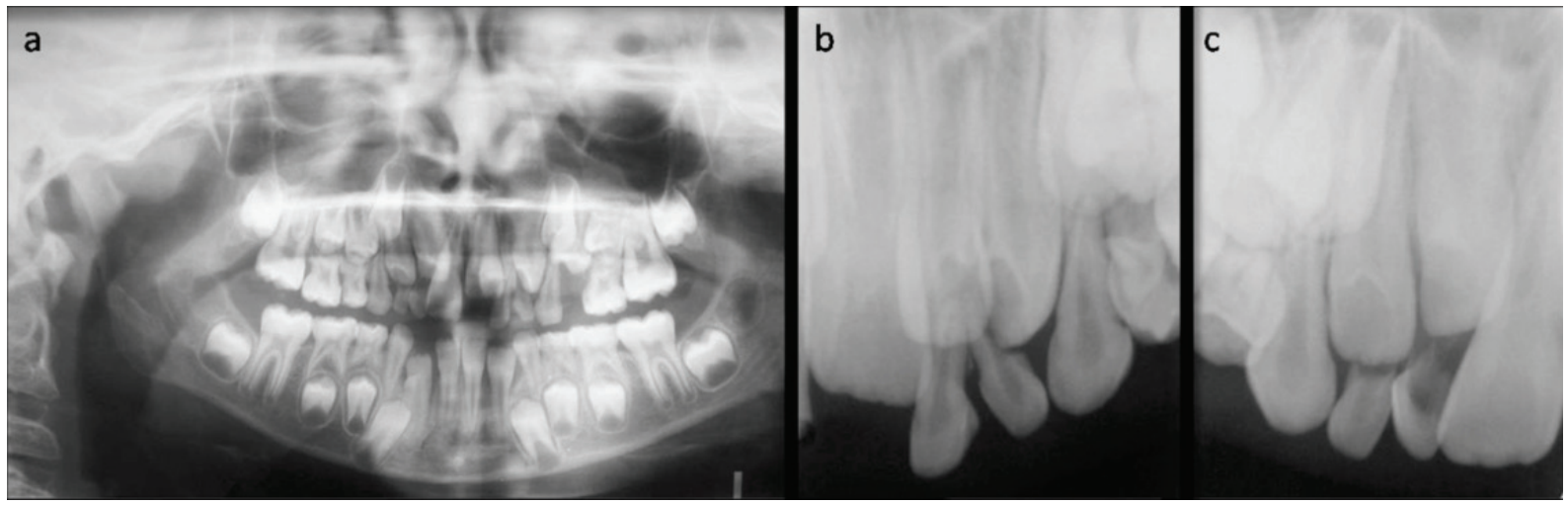

Figure 2. a. Panoramic radiograph, b and c. periapical radiographs.

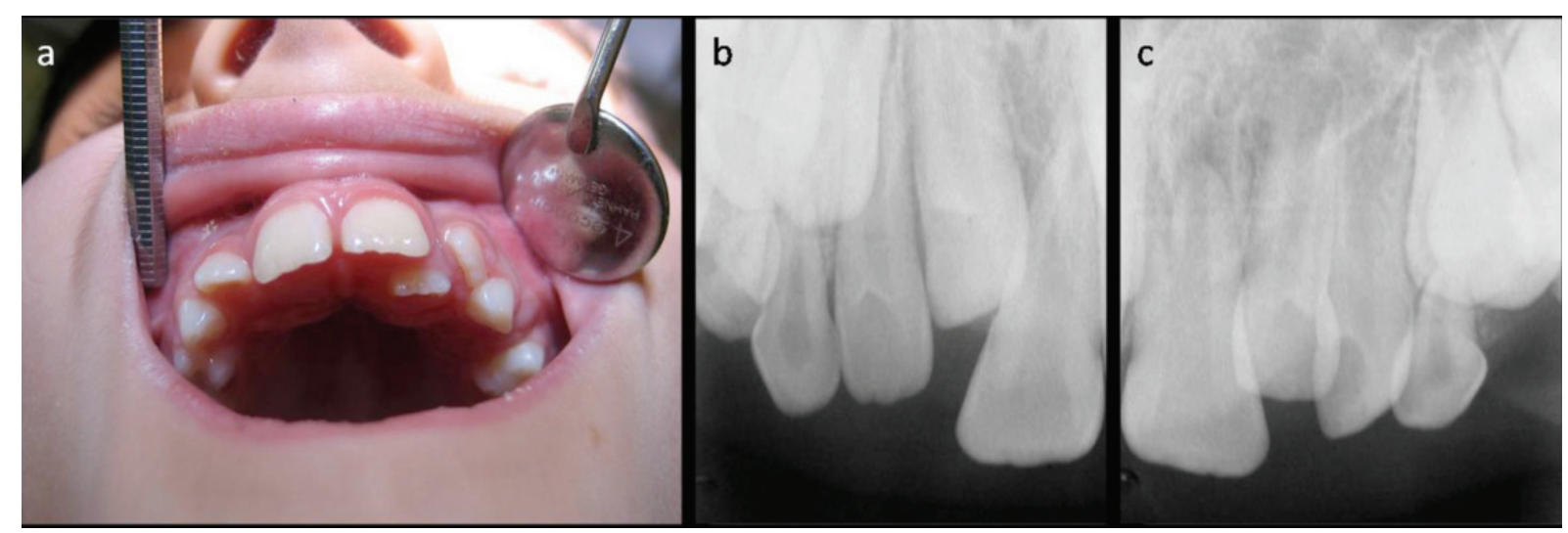

Figure 3. a. Intraoral view b and c. periapical radiographs after 8 months. 
ed tooth. A maxillary left lateral incisor that had erupted in the palatinal regions was also extracted, as two maxillary left lateral incisors of similar shape were present. The mucoperiosteal flap was raised, and the impacted maxillary right lateral incisor was extracted (Figure 4). Sutures were removed 1 week following extraction, and the patient was recalled for tri-monthly clinical and radiographic examinations in order to closely follow the eruption pathways of the remaining teeth (Figure 5). At 10 months of follow-up, no root resorption or loss of vitality was observed in the adjacent teeth (Figure 6). Some rotation of the maxillary left lateral incisor and a super Class I occlusion in the buccal segment was observed.

\section{DISCUSSION}

According to the literature, supernumerary teeth are rarely observed in deciduous dentition. Humerfelt et $\mathrm{al}^{8}$ point out that hyperdontia in primary dentition is often overlooked because the additional teeth often erupt normally, are of normal shape and appear to be in proper alignment, as in the case reported here. While the infrequent reporting of supernumerary deciduous teeth may

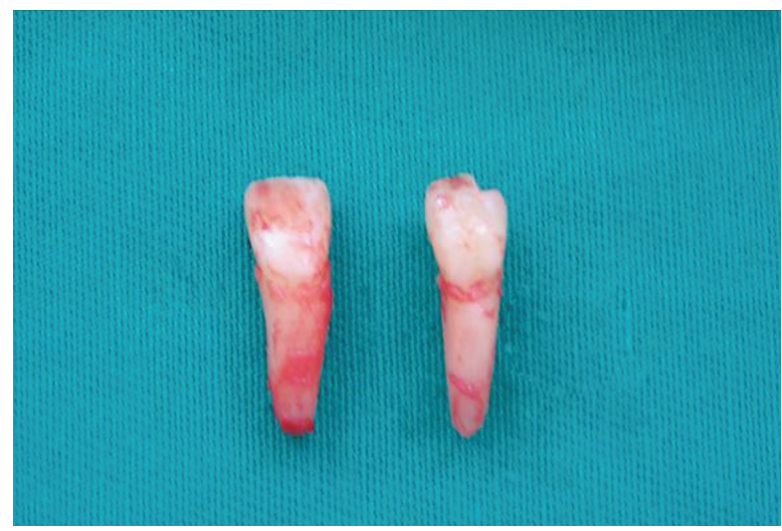

Figure 4. Supernumerary teeth after extraction.

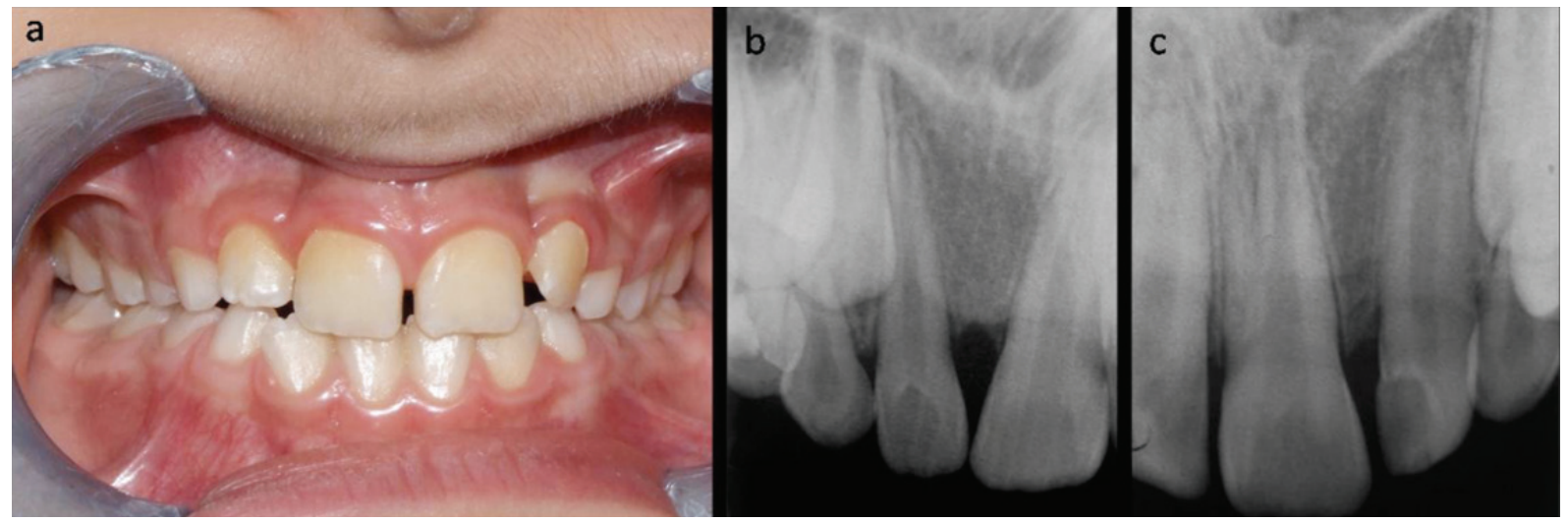

Figure 6. a. Intraoral view b and c. periapical radiographs 10 months after extraction. 
dible or both. ${ }^{1,3,14}$ Bilateral cases are rare, making up only $8 \%$ of the total. A literature search found only five reports of bilateral maxillary central incisor duplication. ${ }^{15-18}$

Multiple supernumerary teeth are reported to be associated with a number of syndromes, including cleft lip and palate, cleidocranial dysostosis, Gardner's syndrome and Chondroectodermal dysplasia. Although multiple supernumerary teeth that are not associated with any syndrome are extremely rare, ${ }^{3}$ no syndrome was identified in the case reported here.

Hyperdontia observed in primary dentition should alert the clinician to the possibility of hyperdontia in the permanent dentition. A careful radiographic survey of both dental arches will provide the clinician and the parents with a preview of any potential problems likely to develop during the course of the child's growth and development. ${ }^{19}$ In the case reported here, supplemental teeth in the primary dentition were superseded by supplemental teeth in the same location in the permanent dentition.

Various complications are associated with supernumerary teeth, including impaction, delayed eruption, or ectopic eruption of adjacent teeth; crowding; development of median diastema; eruption into the floor of the nasal cavity; formation of primordial or follicular cysts, with significant bone destruction; root resorption of adjacent teeth; and esthetic problems, including those associated with crowding. 1,2,6,20,21 In making decisions related to extraction of extra teeth, if two teeth are equally well formed, the tooth that is displaced the most should be extracted. ${ }^{13}$

\section{CONCLUSIONS}

Supernumerary teeth can cause problems in the eruption and alignment of normal dentition. Early diagnosis and treatment are therefore important to prevent complications.

\section{REFERENCES}

1. Primosch RE. Anterior supernumerary teeth-assessment and surgical intervention in children. Pediatr Dent $1981 ; 3: 204-215$.

2. Garvey MT, Barry HJ, Blake M. Supernumerary teeth--an overview of classification, diagnosis and management. $J$ Can Dent Assoc 1999;65:612-616.
3. Scheiner MA, Sampson WJ. Supernumerary teeth: a review of the literature and four case reports. Aust Dent $J$ 1997;42:160-165.

4. Luten JR Jr. The prevalence of supernumerary teeth in primary and mixed dentitions. ASDC J Dent Child 1967;34:346353.

5. Kaler LC. Prevalence of mesiodens in a pediatric Hispanic population. ASDC J Dent Child 1988;55:137-138.

6. Tay F, Pang A, Yuen S. Unerupted maxillary anterior supernumerary teeth: report of 204 cases. ASDC J Dent Child 1984;51:289-294.

7. Koch H, Schwartz O, Klausen B. Indications for surgical removal of supernumerary teeth in the premaxilla. Int J Oral Maxillofac Surg 1986;15:273-281.

8. Humerfelt D, Hurlen B, Humerfelt S. Hyperdontia in children below four years of age: a radiographic study. ASDC $J$ Dent Child 1985;52:121-124.

9. Taylor GS. Characteristics of supernumerary teeth in the primary and permanent dentitions. Dent Pract Dent Rec 1972:22;203-208.

10. Jarvinen S, Lehtinen L. Supernumerary and congenitally missing primary teeth in Finnish children. Acta Odontol Scand 1981;39:83-86.

11. Winter GB, Brook AH. Tooth abnormalities. In: Rowe $A H$, Alexander G, John B (ed.). Clinical Dentistry. Oxford: Blackwell Scientific Publications, 1986:55-103.

12. Gelin ME. The distribution of anomalies of primary anterior teeth and their effect on permanent successors. Dent Clin North Am 1984;28:69-80.

13. Sharma A. Mandibular midline supernumerary tooth: a case report. J Indian Soc Pedo Prev Dent 2001;19:143-144.

14. Liu JF. Characteristics of premaxillary supernumerary teeth: a survey of 112 cases. ASDC J Dent Child 1995;62:262265.

15. Rock WP. A case of bilateral supplemental central incisors. Int J Paediatr Dent 1991;1:155-158.

16. Steelman R, Wilson C, Nelson S. Maxillary incisor duplication. Oral Surg Oral Med Oral Pathol 1991;71:523.

17. Trotman CA, McNamara T. Four maxillary incisors: a case report. Spec Care Dentist 1994:14;112-115.

18. Tomizawa A, Shimizu A, Hayashi S, Noda T. Bilateral maxillary fused primary incisors accompanied by succedaneous supernumerary teeth: report of a case. Int J Paediatr Dent 2002; 12:223-227.

19. Pashley EL. Hyperdontia in the primary dentition: report of case. ASDC J Dent Child 1987;54:60-61.

20. Mitchell L. Supernumerary teeth. Dent Update 1989;16:65$66,68-69$. 
21. Hogstrom A, Andersson L. Complications related to surgical removal of anterior supernumerary teeth in children. ASDC J Dent Child 1987;54:341-343.

22. Hattab EN, Yassin OM, Rawashdeh MA. Supernumerary teeth: report of three cases and review of the literature. ASDC J Dent Child 1994;61:382-393. 